\title{
Cross section measurements of the reactions induced by deuteron particles on ${ }^{13} \mathrm{C}$
}

\author{
Julien L. Colaux, Tristan Thomé and Guy Terwagne \\ Laboratoire d'Analyses par Réactions Nucléaires, University of Namur, B-5000 \\ Namur, Belgium
}

Abstract

Nuclear reactions induced by deuterons have been found to be an ideal analysis tool for depth profiling of light elements in the first microns of materials. In particular, the non resonant nuclear reactions $(\mathrm{d}, \mathrm{p}),(\mathrm{d}, \alpha)$ and $(\mathrm{d}, \mathrm{t})$ are well adapted to determine depth distributions of ${ }^{12} \mathrm{C}$ and ${ }^{13} \mathrm{C}$ in a single measurement. Nevertheless, only the cross section of the ${ }^{12} \mathrm{C}\left(\mathrm{d}, \mathrm{p}_{0}\right){ }^{13} \mathrm{C}$ nuclear reaction is well known for various experimental configurations. Thus, we measured the differential cross sections of the ${ }^{13} \mathrm{C}\left(\mathrm{d}, \mathrm{p}_{0}\right){ }^{14} \mathrm{C},{ }^{13} \mathrm{C}\left(\mathrm{d}, \mathrm{\alpha}_{0}\right){ }^{11} \mathrm{~B}$, ${ }^{13} \mathrm{C}\left(\mathrm{d}, \alpha_{1}\right){ }^{11} \mathrm{~B}$ and ${ }^{13} \mathrm{C}\left(\mathrm{d}, \mathrm{t}_{0}\right){ }^{12} \mathrm{C}$ nuclear reactions. A thin ${ }^{13} \mathrm{C}$ foil $(83 \mathrm{~nm}$ thick $)$ was used and the measurements were performed at deuteron energies from 0.5 to $1.65 \mathrm{MeV}$ for different laboratory angles of detection $\left(135^{\circ}, 150^{\circ}\right.$ and $165^{\circ}$ with respect to the incident beam). Then, the results obtained in this work were compared to cross sections measured by J. B. Marion and G. Weber for a detection angle of $135^{\circ}$.

PACS codes : 25.45.De, 29.30.Ep

Keywords : cross section, ${ }^{13} \mathrm{C}$, NRA, ${ }^{13} \mathrm{C}(\mathrm{d}, \mathrm{p}){ }^{14} \mathrm{C},{ }^{13} \mathrm{C}(\mathrm{d}, \alpha){ }^{11} \mathrm{~B},{ }^{13} \mathrm{C}(\mathrm{d}, \mathrm{t}){ }^{12} \mathrm{C}$

Corresponding author: J. L. Colaux, FUNDP, rue de Bruxelles, 61-B5000 Namur, Belgium

e-mail : julien.colaux@fundp.ac.be

Phone: + $32(0) 81725479$ - Fax : + $32(0) 81725474$ 


\section{Introduction}

Ion beam analysis has been applied for many years to measure carbon

3 concentrations and depth profiles, and to perform stable isotopic tracing using materials

4 enriched in ${ }^{13} \mathrm{C}$. The use of the narrow resonance $(\Gamma=75 \mathrm{eV})$ at $1748 \mathrm{keV}$ of ${ }^{13} \mathrm{C}(\mathrm{p}, \gamma){ }^{14} \mathrm{~N}$

5 reaction is particularly well adapted to obtain ${ }^{13} \mathrm{C}$ areal densities and profiles with high

6 depth resolution [1]. Nevertheless this method does not allow to determine depth

7 distributions of other carbon isotopes with a single measurement. In that case, the non

8 resonant nuclear reactions $(\mathrm{d}, \mathrm{p}),(\mathrm{d}, \alpha)$ and $(\mathrm{d}, \mathrm{t})$ are required. Indeed, proton, alpha and

9 triton particles are emitted at different energies from ${ }^{12} \mathrm{C}\left(\mathrm{d}, \mathrm{p}_{0}\right){ }^{13} \mathrm{C},{ }^{13} \mathrm{C}\left(\mathrm{d}, \mathrm{p}_{0}\right){ }^{14} \mathrm{C}$,

$10{ }^{13} \mathrm{C}\left(\mathrm{d}, \alpha_{0}\right){ }^{11} \mathrm{~B},{ }^{13} \mathrm{C}\left(\mathrm{d}, \alpha_{1}\right){ }^{11} \mathrm{~B}$ and ${ }^{13} \mathrm{C}\left(\mathrm{d}, \mathrm{t}_{0}\right){ }^{12} \mathrm{C}$ reactions. Thus, despite a poorer depth

11 resolution than that available with resonance techniques, these nuclear reactions can be

12 used to depth profile ${ }^{12} \mathrm{C}$ and ${ }^{13} \mathrm{C}$ simultaneously.

13 The exploitation of these nuclear reactions to depth profile light elements requires

14 the use of accurate cross sections. The ${ }^{12} \mathrm{C}\left(\mathrm{d}, \mathrm{p}_{0}\right){ }^{13} \mathrm{C}$ cross section is well known at

15 deuteron energies from 0.8 to $1.1 \mathrm{MeV}$ and has been recently measured again [2], which is

16 not the case for nuclear reactions induced by deuterons on ${ }^{13} \mathrm{C}[3,4]$. Thus, differential

17 cross sections of the ${ }^{13} \mathrm{C}\left(\mathrm{d}, \mathrm{p}_{0}\right){ }^{14} \mathrm{C},{ }^{13} \mathrm{C}\left(\mathrm{d}, \alpha_{0}\right){ }^{11} \mathrm{~B},{ }^{13} \mathrm{C}\left(\mathrm{d}, \alpha_{1}\right){ }^{11} \mathrm{~B}$ and ${ }^{13} \mathrm{C}\left(\mathrm{d}, \mathrm{t}_{0}\right){ }^{12} \mathrm{C}$ reactions

18 were measured in this energy range, using a thin self supported ${ }^{13} \mathrm{C}$ foil. The composition

19 and the thickness of this foil were checked by Rutherford Backscattering Spectroscopy

20 (RBS) and profilometry. The well known carbon build-up phenomenon occurring during

21 beam irradiation [5] was determined and taken into account in this work. Finally, our 
1 results were compared to the ones obtained fifty years ago by J. B. Marion and G. Weber $2[3,4]$.

\section{$3 \quad 2$ Experimental}

4 Three silicon surface barrier detectors (700 $\mu \mathrm{m}$ depleted zone) were used for the detection

5 of charged particles emitted by nuclear reactions. The detectors were respectively

6 positioned at $135^{\circ}, 150^{\circ}$ and $165^{\circ}$ with respect to the incident beam (solid angle of $\sim 2.1$

7 msr). The RBS and NRA analyses were performed, without any absorber, in this geometry

8 with ALTAÏS ${ }^{1}$, a 2 MV Tandetron accelerator installed at the University of Namur

9 (Belgium). The incident beam had a $1 \mathrm{~mm}$ diameter section on the target and the vacuum

10 pressure did not exceed $5 \times 10^{-6} \mathrm{~Pa}$. The uncertainty on the accelerator energy was less

11 than $200 \mathrm{eV}[6]$.

12 The thin ${ }^{13} \mathrm{C}$ foil used for cross section measurements was provided by ACF metals.

13 The thickness given by the manufacturer $(82 \pm 8 \mathrm{~nm})$ was checked by profilometry using a

14 Surface Profile Measuring System Dektak from Veeco Instruments. Its composition was

15 determined by RBS using a $1 \mathrm{MeV}{ }_{2}^{4} \mathrm{He}$ beam. The incident current was approximately

$1620 \mathrm{nA}$. This method may only be used for incident $\alpha$ energies lower than $2 \mathrm{MeV}$, because

17 above this energy, deviations with respect to Rutherford backscattering become too

18 significant [7]. A very thin film of gold was deposited on the ${ }^{13} \mathrm{C}$ foil by magnetron

19 sputtering technique. The deposition time was controlled in order to obtain a film of about

$2030 \times 10^{15}$ at.cm ${ }^{-2}$ and its exact thickness $\left(32.2 \pm 0.6 \times 10^{15}\right.$ at. $\left.\mathrm{cm}^{-2}\right)$ was determined by RBS

\footnotetext{
${ }^{1}$ Accélérateur Linéaire Tandetron pour l'Analyse et l'Implantation des Solides
} 
1 using a $1 \mathrm{MeV}_{2}^{4} \mathrm{He}$ beam. Then, the number of incident particles $N_{i}$ and the solid angle of

2 detection $\Omega$, were determined using the following equation:

$$
N_{i} \times \Omega=\frac{A_{A u}}{N_{A u} \times\left(\frac{\mathrm{d} \sigma}{\mathrm{d} \Omega}\right)_{A u}}
$$

4 where $A_{A u}$ is the number of particles backscattered by gold nuclei (area of the gold peak),

$5 N_{A u}$ is the areal density of gold $\left(\right.$ at.cm $\left.{ }^{-2}\right)$ and $\left(\frac{\mathrm{d} \sigma}{\mathrm{d} \Omega}\right)_{A u}$ is the theoretical elastic cross

6 section for gold obtained by Rutherford formula.

NRA measurements were performed at deuteron energies ranging from 0.5 to

$8 \quad 1.65 \mathrm{MeV}$ by 25 or $50 \mathrm{keV}$ energy steps. The incident current was approximately $250 \mathrm{nA}$.

9 A faraday cup positioned behind the thin ${ }^{13} \mathrm{C}$ foil allowed us to measure the beam current

10 in order to monitor the time of each acquisition. A ring biased at $-150 \mathrm{~V}$ was placed

11 between the thin carbon foil and the faraday cup in order to prevent secondary electrons to

12 escape. The charge integrated into the faraday cup was $100 \mu \mathrm{C}$ for each energy step. By

13 using the $N_{i} \times \Omega$ product given by Equation 1, the differential cross sections of

$14{ }^{13} \mathrm{C}\left(\mathrm{d}, \mathrm{p}_{0}\right){ }^{14} \mathrm{C},{ }^{13} \mathrm{C}\left(\mathrm{d}, \alpha_{0}\right){ }^{11} \mathrm{~B},{ }^{13} \mathrm{C}\left(\mathrm{d}, \alpha_{1}\right){ }^{11} \mathrm{~B},{ }^{13} \mathrm{C}\left(\mathrm{d}, \mathrm{t}_{0}\right){ }^{12} \mathrm{C}$ reactions were determined by the

15 following relation :

$$
\left(\frac{d \sigma}{d \Omega}\right)=\frac{A_{C}}{A_{A u}} \frac{N_{A u}}{N_{C}}\left(\frac{d \sigma}{d \Omega}\right)_{A u}
$$

18 where $A_{C}$ is the number of emitted particles by the nuclear reaction under study and $N_{C}$ is 19 the ${ }^{13} \mathrm{C}$ areal density of the thin foil $\left(\mathrm{at}_{\mathrm{cm}}{ }^{-2}\right)$. This technique of gold marker is very 
1 effective to decrease the error made on the measurement of the solid angle of detection and

2 the number of incident particles.

\section{Results and discussion} 21 Q-values (respectively 5.952, 5.169, 3.044 and $1.311 \mathrm{MeV}$ ), give rise to well separated

The composition of the thin ${ }^{13} \mathrm{C}$ foil was determined from the simulations of experimental RBS spectra performed with SIMNRA code (Table I) [8]. These measurements show the presence of contamination layers on both sides of the foil. These contamination layers (thickness of $3 \times 10^{16}$ at. $\mathrm{cm}^{-2}$ ) are composed of about 92 atomic percent of carbon and 8 atomic percent of oxygen. The ${ }^{12} \mathrm{C}$ and ${ }^{16} \mathrm{O}$ isotopes were also detected in the bulk of the foil, at respectively 1.5 and 0.5 atomic percent. Finally, the ${ }^{13} \mathrm{C}$ areal density of the thin foil was determined to be $(8.63 \pm 0.22) \times 10^{17}$ at. $\mathrm{cm}^{-2}$ which corresponds to an energy loss of $6 \mathrm{keV}$ for a $1 \mathrm{MeV}$ deuteron beam. The measured thickness $(83 \pm 2 \mathrm{~nm})$ corresponds to the one determined by profilometry $(89 \pm 8 \mathrm{~nm})$ and given by the manufacturer $(82 \pm 8 \mathrm{~nm})$.

A typical spectrum obtained at $165^{\circ}$ with $1.05 \mathrm{MeV}$ deuteron particles is shown in Figure 1 . The very intense peak labeled $\mathrm{Au}_{\mathrm{RBS}}$ and observed at $1 \mathrm{MeV}$ corresponds to the deuteron particles backscattered by thin film of gold. The peaks labeled ${ }^{13} \mathrm{Cp}_{0}$ and ${ }^{13} \mathrm{C} \alpha_{0}$ are due to respectively ${ }^{13} \mathrm{C}\left(\mathrm{d}, \mathrm{p}_{0}\right){ }^{14} \mathrm{C}$ and ${ }^{13} \mathrm{C}\left(\mathrm{d}, \alpha_{0}\right){ }^{11} \mathrm{~B}$ nuclear reactions. The same notation is adopted for all the reactions induced by deuterons on other elements. The ${ }^{13} \mathrm{C}\left(\mathrm{d}, \mathrm{p}_{0}\right){ }^{14} \mathrm{C}$, ${ }^{13} \mathrm{C}\left(\mathrm{d}, \alpha_{0}\right){ }^{11} \mathrm{~B},{ }^{13} \mathrm{C}\left(\mathrm{d}, \alpha_{1}\right){ }^{11} \mathrm{~B}$ and ${ }^{13} \mathrm{C}\left(\mathrm{d}, \mathrm{t}_{0}\right){ }^{12} \mathrm{C}$ nuclear reactions, that present different 
1 peaks (respectively at 5.9, 3.7, 2.3 and $1.3 \mathrm{MeV}$ ) with almost no background. The area

2 under each peak, which corresponds to the number of emitted particles detected for a given

3 solid angle, and the area of the gold peak can be directly used into Equation 2 to calculate

4 the corresponding cross section. The peak detected around $3 \mathrm{MeV}$ corresponds to the

$5{ }^{12} \mathrm{C}\left(\mathrm{d}, \mathrm{p}_{0}\right){ }^{13} \mathrm{C}$ nuclear reaction and allows us to characterize the carbon build-up

6 phenomenon occurring during the analyses. This very slight carbon contamination

7 increased linearly with the integrated charge and was determined to be

$8(0.017 \pm 0.001) \times 10^{15}$ at. $\mathrm{cm}^{-2} \cdot \mu \mathrm{C}^{-1}$. It represents a ${ }^{13} \mathrm{C}$ areal density increase lower than

$910^{15}$ at. $^{-2}$ for a complete run of analysis (about $3000 \mu \mathrm{C}$ ) and was neglected for the

10 determination of the differential cross section intensity.

11 The differential cross sections of the ${ }^{13} \mathrm{C}\left(\mathrm{d}, \mathrm{p}_{0}\right){ }^{14} \mathrm{C},{ }^{13} \mathrm{C}\left(\mathrm{d}, \mathrm{\alpha}_{0}\right){ }^{11} \mathrm{~B},{ }^{13} \mathrm{C}\left(\mathrm{d}, \mathrm{\alpha}_{1}\right){ }^{11} \mathrm{~B}$ and

$12{ }^{13} \mathrm{C}\left(\mathrm{d}, \mathrm{t}_{0}\right){ }^{12} \mathrm{C}$ nuclear reactions calculated from Equation 2 for $135^{\circ}, 150^{\circ}$ and $165^{\circ}$

13 laboratory detection angles are presented in Figure 2 to Figure 5 and will be available in the

14 electronic IBANDL data base [9]. The absolute uncertainty on the cross sections is

15 estimated at $4.5 \%$ in the energy range from $800 \mathrm{keV}$ to $1650 \mathrm{keV}$ and does not exceed

$1610 \%$ out of this range. It takes into account the uncertainties on the measurement of the

$17{ }^{13} \mathrm{C}$ foil composition $(2.5 \%)$, the areal density of gold $(2.0 \%)$, the number of emitted

18 particles originating from the nuclear reactions under study $(<3 \%)$ and the number of

19 deuteron backscattered by gold nuclei $(<0.5 \%)$. The energy scale was corrected in order to

20 indicate the deuteron energy in center of the thin carbon foil. This correction takes into

21 account the energy lost by deuteron beam into carbon contamination layer, thin film of gold

22 and thin ${ }^{13} \mathrm{C}$ foil. On the other hand, reference curves are uncorrected for target thickness

23 used by Marion [3,4]. This is the reason why the cross sections measured in this work are 
1 systematically shifted of about $30 \mathrm{keV}$ compared to those values (Figure 2.a, Figure 3.a and

2 Figure 5.a).

The ${ }^{13} \mathrm{C}\left(\mathrm{d}, \mathrm{p}_{0}\right){ }^{14} \mathrm{C}$ cross section measured at $135^{\circ}$ (Figure 2.a) is in very good

4 agreement with the one measured by J. B. Marion and G. Weber [3]. The shape of the cross

5 sections obtained at $135^{\circ}$ for the ${ }^{13} \mathrm{C}\left(\mathrm{d}, \alpha_{0}\right){ }^{11} \mathrm{~B}$ and ${ }^{13} \mathrm{C}\left(\mathrm{d}, \mathrm{t}_{0}\right){ }^{12} \mathrm{C}$ reactions (Figure 3.a and

6 Figure 5.a) is also in good agreement with the one from reference [4]. Nevertheless, we

7 note significant differences in the intensity of these cross sections. This disagreement is due

8 to the experimental procedure followed by Marion. Indeed, to facilitate the data acquisition

9 with the magnetic spectrometer system [4], Marion has only measured the maximum of

10 counting rate and not the area under the ${ }^{13} \mathrm{C \alpha}_{0}$ and ${ }^{13} \mathrm{Ct}_{0}$ peaks. This method is correct at

11 high bombarding energy where the maximum of each peak is directly proportional to its surface. Nevertheless, at low deuteron energies the straggling of particles in carbon foil 13 increases the width of the peak and its maximum is no more proportional to its area. In 14 order to resolve this problem, a single empirical correction curve was established and 15 applied to ${ }^{13} \mathrm{C}_{0}$ and ${ }^{13} \mathrm{Ct}_{0}$ cross sections [4]. However, the nature and the energy of 16 particles emitted in these reactions are very different. It is not correct to apply the same 17 correction curve to the two cross sections. So the single empirical correction curve used by

18 Marion leads to an overestimation of the ${ }^{13} \mathrm{C}\left(\mathrm{d}, \alpha_{0}\right){ }^{11} \mathrm{~B}$ cross section of about 25 percent 19 and to an undervaluation of the ${ }^{13} \mathrm{C}\left(\mathrm{d}, \mathrm{t}_{0}\right){ }^{12} \mathrm{C}$ cross section of about 10 percent.

20 Finally, it is interesting to note that all nuclear reactions induced by deuteron on ${ }^{13} \mathrm{C}$ 21 and on ${ }^{12} \mathrm{C}$ emit particles at well separated energies. Moreover these nuclear reactions 22 present a cross section which does not vary much from 0.950 to $1.075 \mathrm{MeV}$. Thus it is 
1 possible to determine ${ }^{13} \mathrm{C}$ and ${ }^{12} \mathrm{C}$ depth distributions simultaneously with a good accuracy

2 working with a deuteron energy around $1.05 \mathrm{MeV}$.

\section{Conclusion}

A thin ${ }^{13} \mathrm{C}$ foil was used to measure differential cross sections of ${ }^{13} \mathrm{C}\left(\mathrm{d}, \mathrm{p}_{0}\right){ }^{14} \mathrm{C}$,

$7 \quad{ }^{13} \mathrm{C}\left(\mathrm{d}, \alpha_{0}\right){ }^{11} \mathrm{~B},{ }^{13} \mathrm{C}\left(\mathrm{d}, \alpha_{1}\right){ }^{11} \mathrm{~B}$ and ${ }^{13} \mathrm{C}\left(\mathrm{d}, \mathrm{t}_{0}\right){ }^{12} \mathrm{C}$ nuclear reactions for deuteron energies from

80.5 to $1.65 \mathrm{MeV}$. These measurements were performed at $135^{\circ}, 150^{\circ}$ and $165^{\circ}$ with respect

9 to the incident beam. The ${ }^{13} \mathrm{C}$ areal density of the thin foil was measured by RBS using a

$10 \quad 1 \mathrm{MeV}{ }_{2}^{4} \mathrm{He}$ beam. The build-up rate of carbon occurring during the analyses was

11 evaluated and the contribution of ${ }^{13} \mathrm{C}$ enrichment to the thin foil was found to be

12 negligible. The energy lost by the deuteron beam into this carbon contamination layer, the

13 gold film and the thin ${ }^{13} \mathrm{C}$ foil was taken into account and the energy scale was corrected in

14 order to indicate the deuteron energy in center of the thin carbon foil. Cross sections

15 obtained for nuclear reactions at a laboratory detection angle of $135^{\circ}$ are in quite good

16 agreement with previous results in the literature [3,4]. The shapes of the cross sections are

17 correct, but significant differences are observed in intensity for the ${ }^{13} \mathrm{C}\left(\mathrm{d}, \alpha_{0}\right){ }^{11} \mathrm{~B}$ and

$18{ }^{13} \mathrm{C}\left(\mathrm{d}, \mathrm{t}_{0}\right){ }^{12} \mathrm{C}$ cross sections. The usage of non resonant $(\mathrm{d}, \mathrm{p}),(\mathrm{d}, \alpha)$ and $(\mathrm{d}, \mathrm{t})$ nuclear

19 reactions allows to depth profile ${ }^{12} \mathrm{C}$ and ${ }^{13} \mathrm{C}$ in a single and relatively rapid measurement.

\section{Acknowledgments}


2 (FUNDP).

3 
2 [1] T. Cabioc'h, E. Thune, M. Jaouen and F. Bodart, Nucl. Instr. and Meth. B 207

3 (2003) 409

4 [2] W. Jiang, V. Shutthanandan, S. Thevuthasan, D.E. McCready, W.J. Weber, Nucl. Instr. Meth. B $222(2004) 538$

6 [3] J. B. Marion and G. Weber, Phys. Rev. 103 (1956) 167

7 [4] J. B. Marion and G. Weber, Phys. Rev. 102 (1956) 1355

8 [5] J. Colaux, G. Terwagne, Nucl. Instr. Meth. B 240 (2005) 429

9 [6] High Voltage Engineering Europa B.V., technical notes about the ALTAÏS 10 accelerator.

11 [7] B.K. Barnes, T.A. Belote, and J.R. Risser, Phys. Rev. 140 (1965) B616

12 [8] M. Mayer, SIMNRA, a Simulation Program for the Analysis of NRA, RBS and 13 ERDA, Proceedings of the $15^{\text {th }}$ International Conference on the Application of 14 Accelerators in Research and Industry, J. L. Duggan and I. L. Morgan (eds.), 15 American Institute of Physics Conference Proceedings 475 (1999) 541.

16 [9] http://www-nds.iaea.org/ibandl/ 


\section{Tables}

2 Table I: Composition of the thin ${ }^{13} \mathrm{C}$ foil according to simulations of experimental RBS spectra performed with SIMNRA code.

\begin{tabular}{|c|c|c|c|c|c|}
\hline \multicolumn{2}{|c|}{$\begin{array}{l}\text { Thickness of layers } \\
\qquad\left(10^{15} \text { at.cm }{ }^{-2}\right)\end{array}$} & 32.2 & 30 & 880 & 30 \\
\hline \multirow{4}{*}{$\begin{array}{l}\text { Composition } \\
\text { (at. \%) }\end{array}$} & ${ }^{198} \mathrm{Au}$ & 100 & 0 & 0 & 0 \\
\hline & ${ }^{13} \mathrm{C}$ & 0 & 1 & 98 & 1 \\
\hline & ${ }^{12} \mathrm{C}$ & 0 & 91 & 1.5 & 91 \\
\hline & ${ }^{16} \mathrm{O}$ & 0 & 8 & 0.5 & 8 \\
\hline
\end{tabular}

\section{4}

5

6 
Figure 1: Typical NRA spectrum obtained at $165^{\circ}$ (lab) by bombardment of $1.05 \mathrm{MeV}$ deuteron particles on the thin ${ }^{13} \mathrm{C}$ foil with areal density of $(8.63 \pm 0.22) \times 10^{17}$ at. $\mathrm{cm}^{-2}$. The incident current was approximately $250 \mathrm{nA}$ and the acquisition time was about 400 seconds (integrated charge of $100 \mu \mathrm{C}$ ).

Figure 3: Differential cross section curves for ${ }^{13} \mathrm{C}\left(\mathrm{d}, \mathrm{\alpha}_{0}\right){ }^{11} \mathrm{~B}$ nuclear reaction measured at $135^{\circ}$ (a), $150^{\circ}$ (b) and $165^{\circ}$ (c) in the laboratory system. Symbols (open squares)

Figure 2: Differential cross section curves for ${ }^{13} \mathrm{C}\left(\mathrm{d}, \mathrm{p}_{0}\right){ }^{14} \mathrm{C}$ nuclear reaction measured at represent the measurements performed in this work while the solid line represents measurements made by J. B. Marion and G. Weber [3].

Figure 5: Differential cross section curves for ${ }^{13} \mathrm{C}\left(\mathrm{d}, \mathrm{t}_{0}\right){ }^{12} \mathrm{C}$ nuclear reaction measured at 23 $135^{\circ}$ (a), $150^{\circ}$ (b) and $165^{\circ}$ (c) in the laboratory system. Symbols (open squares) represent the measurements performed in this work while solid line represents measurements made by J. B. Marion and G. Weber [4]. 


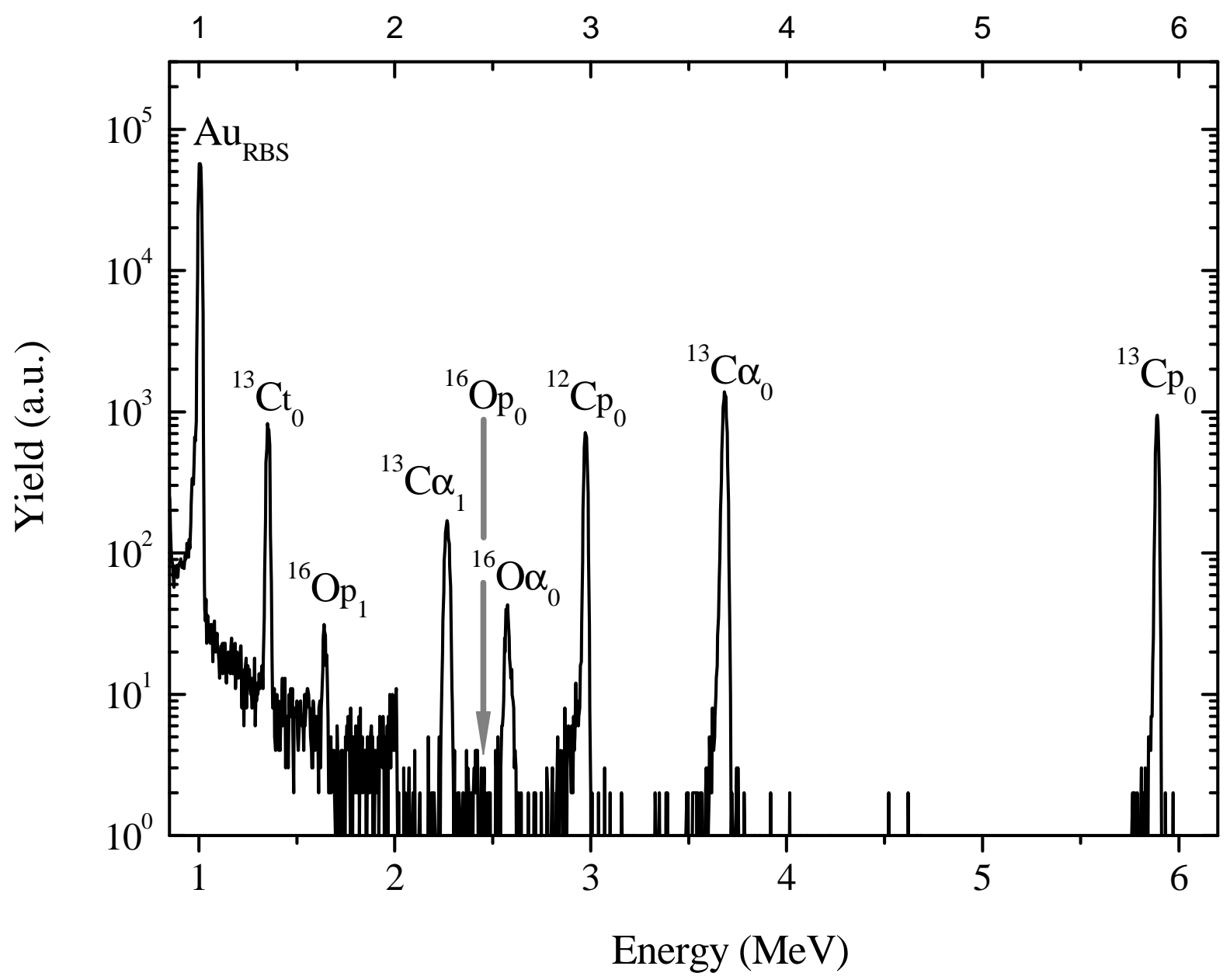

2

Figure 1 


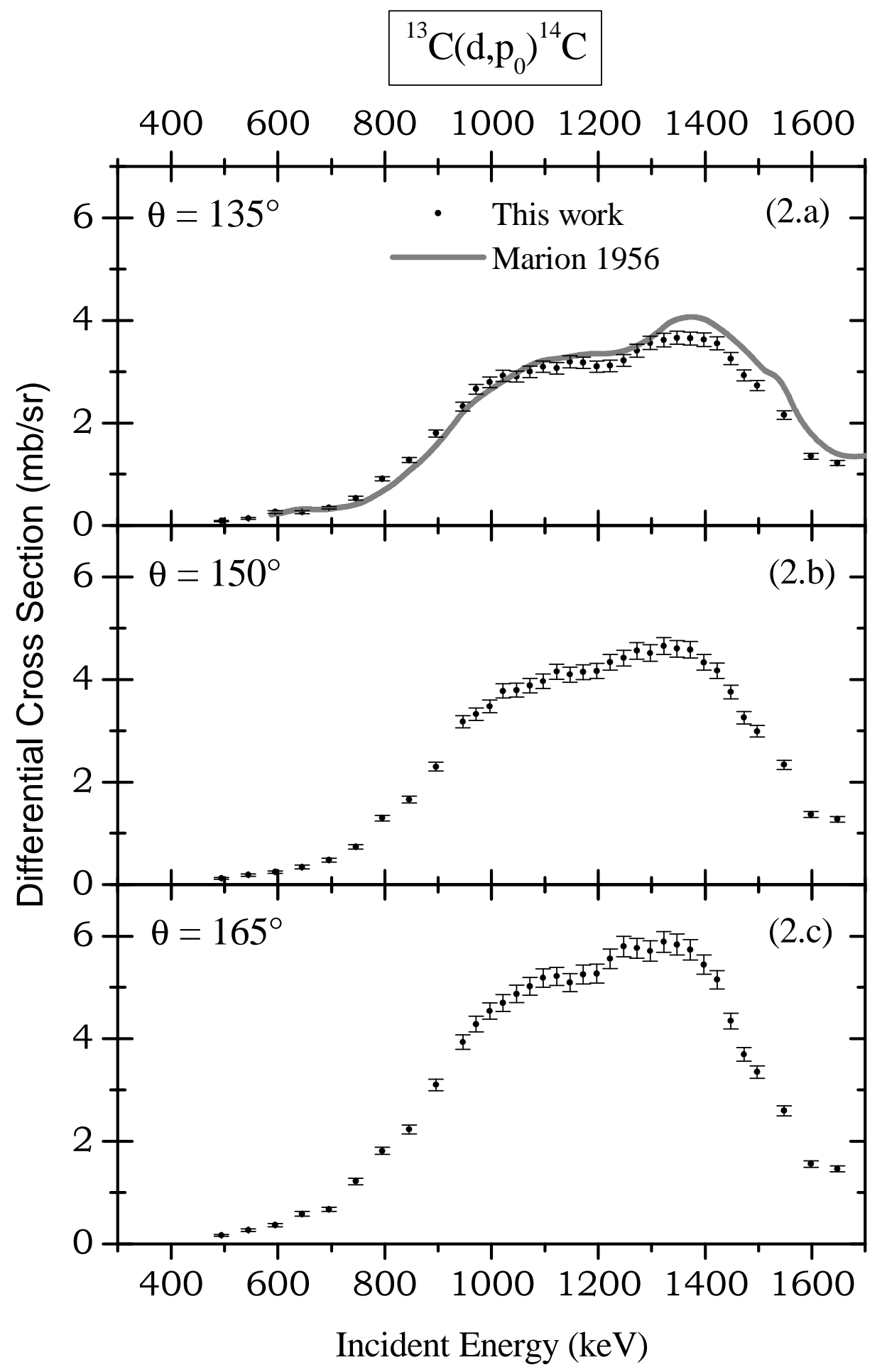

Figure 2 


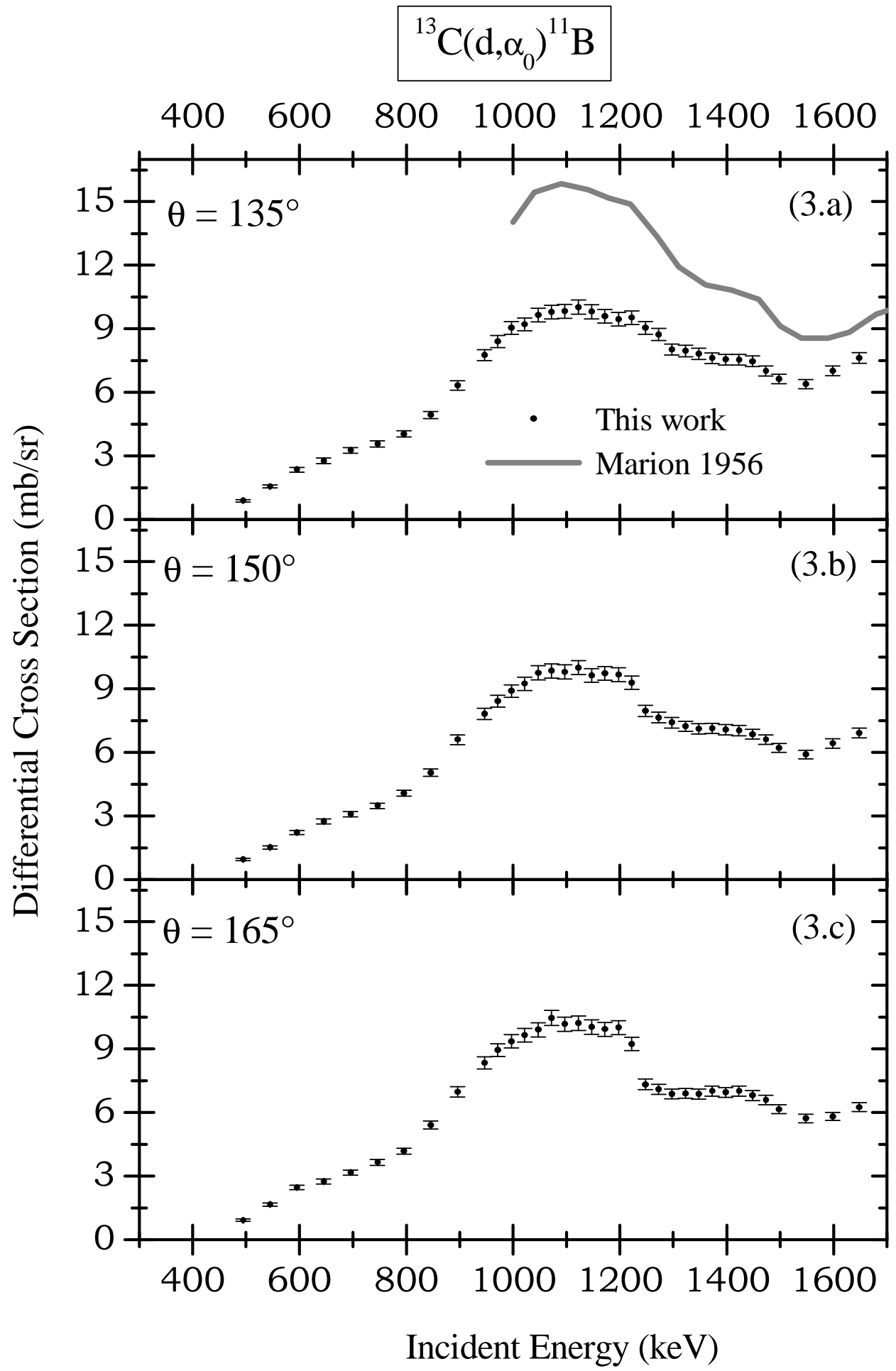




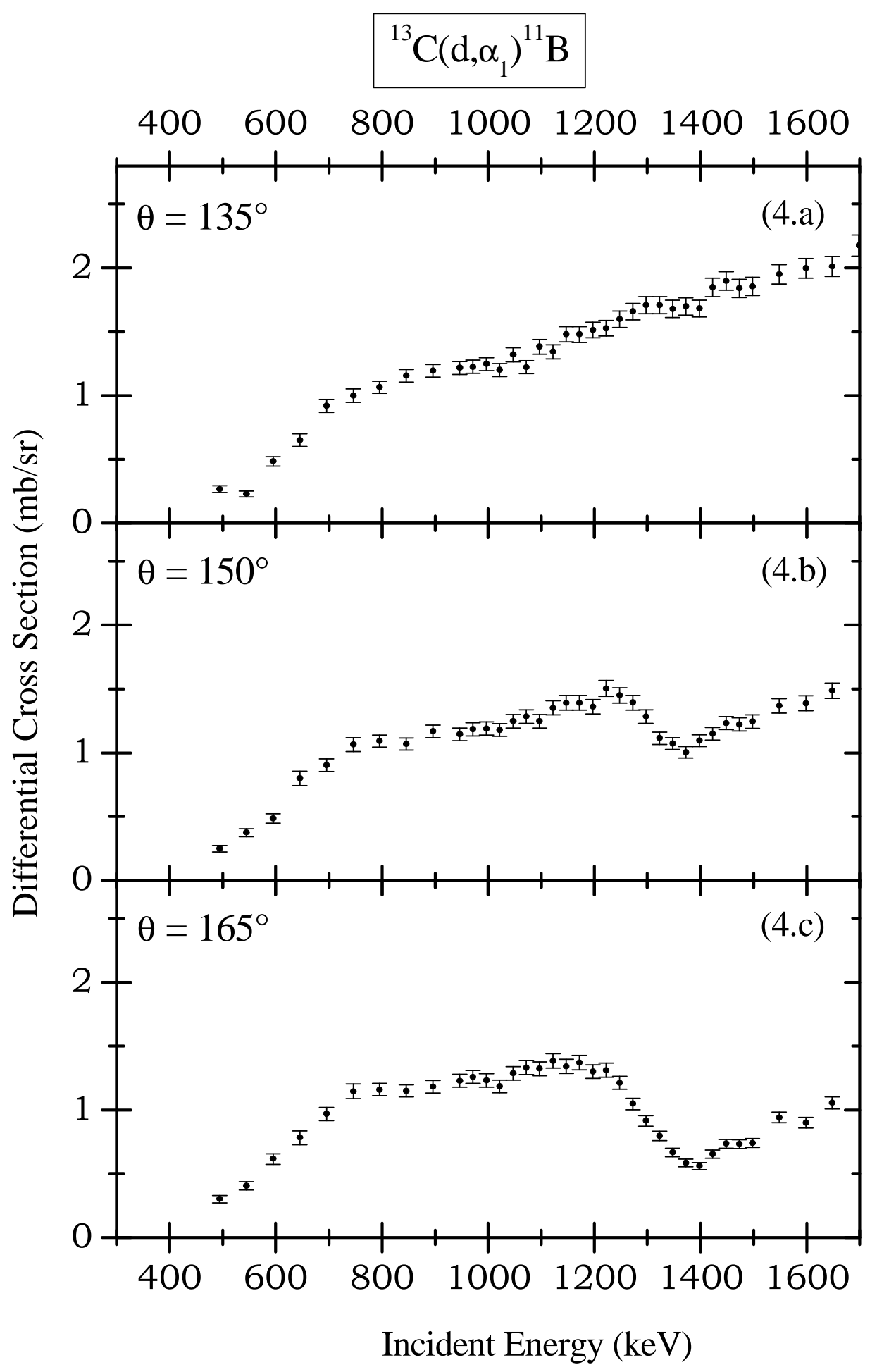

Figure 4 


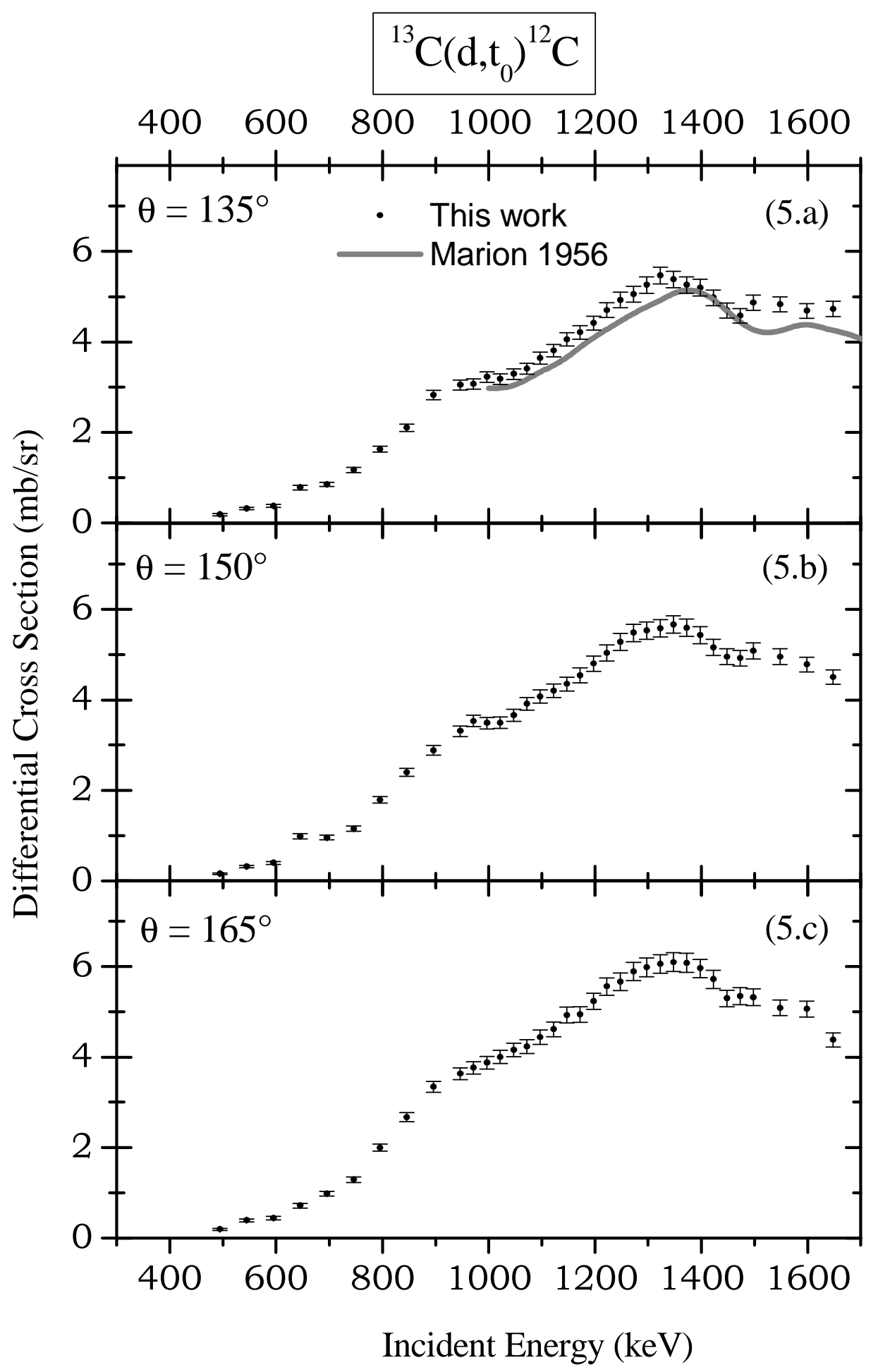

Figure 5 